\title{
Increased dosage of infliximab is a potential cause of Pneumocystis carinii pneumonia
}

\author{
Takuya Iwama, Aki Sakatani, Mikihiro Fujiya*, Kazuyuki Tanaka, Shugo Fujibayashi, Yoshiki Nomura, \\ Nobuhiro Ueno, Shin Kashima, Takuma Gotoh, Junpei Sasajima, Kentaro Moriichi and Katsuya Ikuta
}

\begin{abstract}
Methods: Pneumocystis carinii pneumonia occasionally appears in immunodeficient patients. While several reports have shown that Pneumocystis carinii pneumonia occurred in the early phase of starting infliximab treatment in patients with Crohn's disease (CD), the present case suggests for the first time that an increased dosage of infliximab may also lead to pneumonia.

Results: A 51 -year-old male had been taking $5 \mathrm{mg}$ of infliximab for the treatment of CD for 10 years with no adverse events. Beginning in September 2013, the dose of infliximab had to be increased to $10 \mathrm{mg} / \mathrm{kg}$ because his status worsened. Thereafter, he complained of a fever and cough, and a CT scan revealed ground-glass opacities in the lower lobes of the bilateral lung with a crazy-paving pattern. Bronchoscopy detected swelling of the tracheal mucosa with obvious dilations of the vessels. A polymerase chain reaction using a bronchoalveolar lavage fluid sample detected specific sequences for Pneumocystis jirovecii; thus he was diagnosed with Pneumocystis carinii (jirovecii) pneumonia. After discontinuing infliximab and starting antibiotic treatment, his symptoms and CT findings were dramatically improved.
\end{abstract}

Conclusions: The administration of an increased dosage of infliximab can cause Pneumocystis carinii pneumonia in CD patients.

\section{Background}

Pneumocystis carinii pneumonia occasionally appears in immunodeficient patients, particularly with the administration of chemotherapy. While several reports have shown that infliximab treatment [1-5], which is generally used for the treatment of rheumatoid arthritis and Crohn's disease, can lead to Pneumocystis carinii pneumonia [6-12], to the best of our knowledge, no case has demonstrated the development of pneumonia due to an increased dosage of infliximab treatment. The present case suggests that an increased dosage of infliximab is a potential cause of Pneumocystis carinii pneumonia.

\footnotetext{
*Correspondence: fjym@asahikawa-med.ac.jp

Department of Medicine, Division of Gastroenterology and Hematology/

Oncology, Asahikawa Medical University, 2-1 Midorigaoka-higashi,

Asahikawa, Hokkaido 078-8510, Japan
}

\section{Case}

A 51-year-old male was suffering Crohn's disease (CD) since 1990. The patient's weight was $67 \mathrm{~kg}$. He had the inflammatory type of Crohn's disease, and the area of his lesion was the colon and small intestine. He had no complications, including intra- or extraenteral lesions, or any other systemic disorders. He had been taking $5 \mathrm{mg} /$ $\mathrm{kg}$ of infliximab (total $400 \mathrm{mg}$ ) since 2004 and $0.15 \mathrm{~g} /$ day of 6-mercaptopurine since 2005 . However, he complained of abdominal pain, his Harvey-Bradshaw index scores increased from 5 to 13 , and he subsequently began taking $10 \mathrm{mg} / \mathrm{kg}$ of infliximab (total $650 \mathrm{mg}$ ) from September 2013. In January 2014, he complained of a fever and cough. Laboratory tests on this admission showed high levels of C-reactive protein and anti-mycoplasma antibody while other examination items, including the white blood cell count and T-SPOT, were unremarkable. 
A computed tomography (CT) scan revealed groundglass opacities in the lower lobes of the bilateral lung with a crazy-paving pattern (Fig. 1a). Bronchoscopy detected swelling of the tracheal mucosa with obvious dilations of the vessels (Fig. 2). A bronchoalveolar lavage fluid sample obtained during bronchoscopy included 255 cells/ field with $80 \%$ macrophages, $12 \%$ lymphocytes and $8 \%$ neutrophils. A polymerase chain reaction using the bronchoalveolar lavage fluid sample detected specific sequences for Pneumocystis jirovecii. Taken together, he was diagnosed as having pneumonia due to the combined infection of Mycoplasma and Pneumocystis carinii (jirovecii). The patient stopped infliximab administration and took $2 \mathrm{~g} /$ day of ceftriaxone, $500 \mathrm{mg} /$ day of azithromycin and $400 \mathrm{mg} / 80 \mathrm{mg} /$ day of sulfamethoxazole/trimethoprim; thereafter his symptoms including a fever and cough improved. CT after the antibiotic therapy showed a significant improvement of the ground-glass opacities in the lower lobes of the bilateral lung (Fig. 1b).

\section{Discussion}

The present report demonstrated a case of Pneumocystis carinii pneumonia due to the increased dosage of infliximab. While several cases have demonstrated pneumonia due to Pneumocystis carinii after infliximab treatment, to the best of our knowledge, this is the first case in which an increased dosage of infliximab triggered pneumonia. A summary of previously reported cases and our case of Pneumocystis carinii pneumonia in CD patients is shown in Table 1.

Of the seven cases, five were male and two were female. The age ranged from 8 to 77 years. While Pneumocystis carinii pneumonia appeared at 4 weeks to 29 months after starting infliximab treatment in previous reports, the present case exhibited pneumonia at 120 months

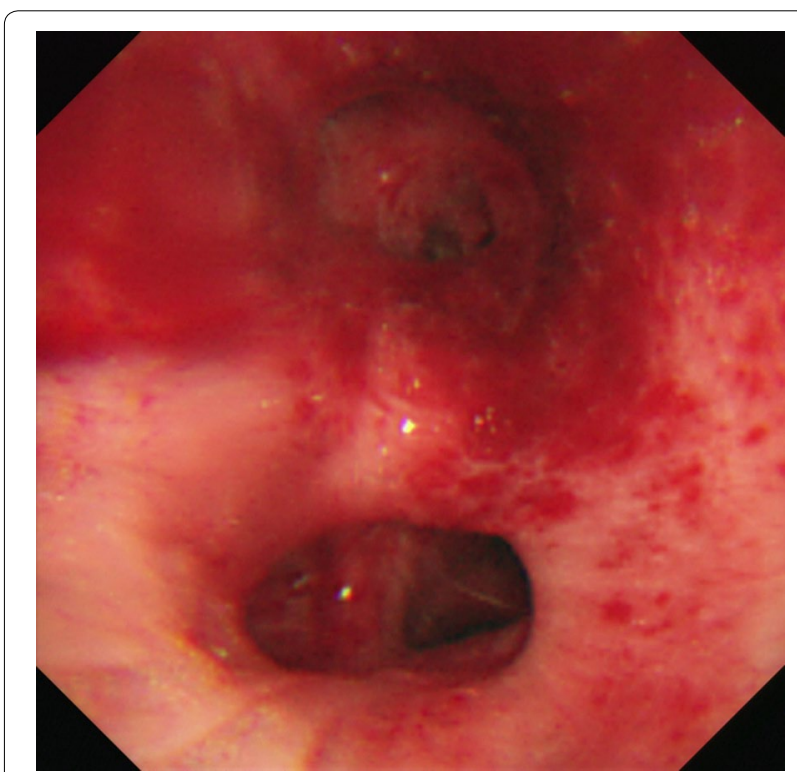

Fig. 2 Bronchoscopy finding. Swelling and obvious dilations of the vessels were seen in the tracheal mucosa on admission

after starting infliximab treatment, at 102 months after starting the 6-mercaptopurine treatment, 24 weeks after starting an increased dosage of infliximab from 5 to $10 \mathrm{mg} / \mathrm{kg}$. This suggests that an increased dosage of infliximab is a potential cause of immunodeficiency, leading to Pneumocystis carinii pneumonia. Notably, all cases developing Pneumocystis carinii pneumonia took immunomodulators and/or steroids, suggesting that the combined use of these drugs is a risk for pneumonia. Because sulfamethoxazole/trimethoprim was effective for all cases, antibiotics should be immediately administered after the diagnosis of Pneumocystis carinii pneumonia.

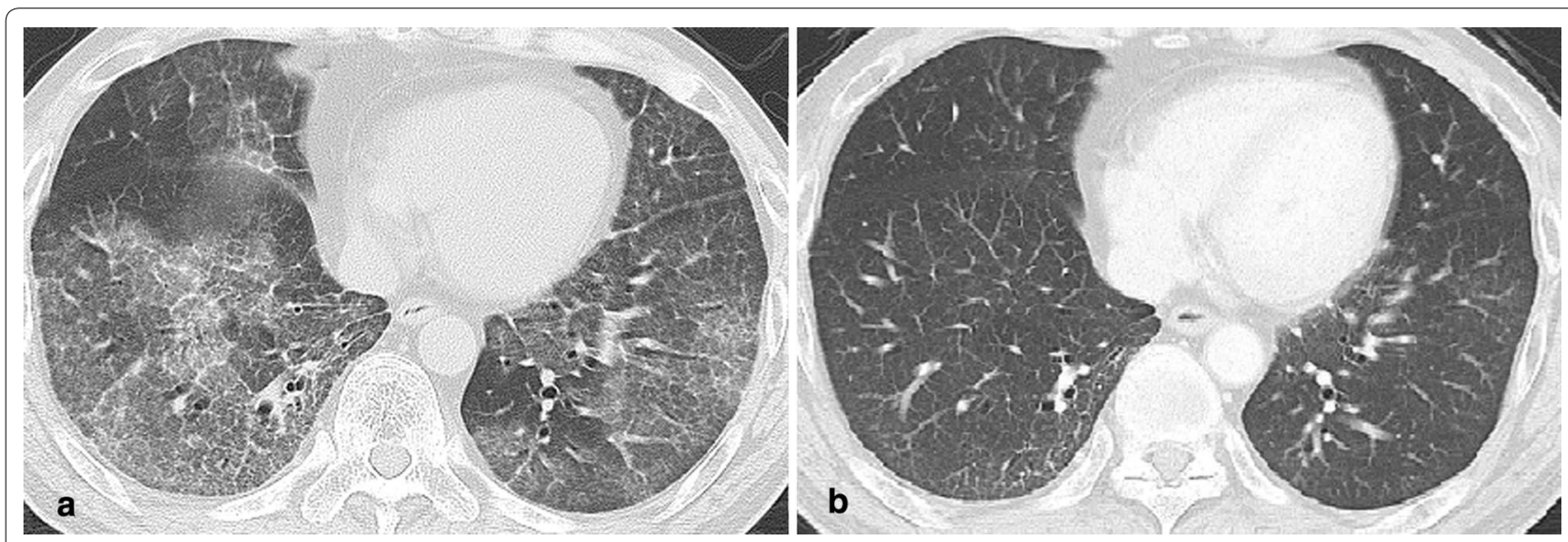

Fig. 1 Computed tomography findings of the chest. Ground-glass opacities were seen in the lower lobes of the bilateral lung with a crazy-paving pattern on admission (a). Ground-glass opacities were improved after antibiotic therapy (b) 
Table 1 Date on pneumocystis pneumonia during administrarion of infliximab

\begin{tabular}{|c|c|c|c|c|c|c|c|c|c|c|}
\hline No. & Reference & Year & Sex & $\begin{array}{l}\text { Age at } \\
\text { diagnosis } \\
\text { (years) }\end{array}$ & $\begin{array}{l}\text { Crohn's } \\
\text { disease } \\
\text { duration }\end{array}$ & IFX duration & Dose of IFX & $\begin{array}{l}\text { Concomitant } \\
\text { drug(s) }\end{array}$ & Medication & Clinical course \\
\hline 1 & Seddik et al. [6] & 2004 & Male & 29 & ND & 1 month & $5 \mathrm{mg} / \mathrm{kg}$ & $P S L+A Z A$ & ST & 2 weeks alive \\
\hline 2 & Velayos et al. [7] & 2004 & Male & 19 & 2 years & $\begin{array}{l}2 \text { years } \\
3 \text { months }\end{array}$ & $5 \mathrm{mg} / \mathrm{kg}$ & $A Z A$ & $\mathrm{ST}+\mathrm{PSL}$ & 2 weeks alive \\
\hline 3 & Kaur et al. [8] & 2004 & Male & 59 & 3 weeks & 9 weeks & ND & PSL & $\mathrm{ST}+\mathrm{PM}$ & 1 month died \\
\hline 4 & Stratakos et al. [9] & 2005 & Female & 77 & 9 months & 8 months & $5 \mathrm{mg} / \mathrm{kg}$ & $\mathrm{mPSL}+\mathrm{AZA}$ & ST & 6 month alive \\
\hline 5 & Itaba et al. [10] & 2007 & Female & 57 & 21 years & 5 weeks & $5 \mathrm{mg} / \mathrm{kg}$ & $P S L+A Z A$ & $\mathrm{ST}+\mathrm{mPSL}$ & 4 month alive \\
\hline 6 & 金井 et al. [11] & 2009 & Male & 69 & 44 years & 4 weeks & $5 \mathrm{mg} / \mathrm{kg}$ & $5-A S A+P S L$ & $\mathrm{ST}+\mathrm{mPSL}$ & 6 month alive \\
\hline 7 & Tshudy et al. [12] & 2010 & Male & 8 & 6 years & 15 months & $5 \mathrm{mg} / \mathrm{kg}$ & None & ST & 4 weeks alive \\
\hline 8 & Present case & 2014 & Male & 51 & 24 years & 10 years & $10 \mathrm{mg} / \mathrm{kg}$ & $\begin{array}{l}\text { 6-MP }(0.15 \mathrm{~g} / \\
\text { day) }\end{array}$ & ST & $\begin{array}{l}1 \text { year } 5 \text { month } \\
\text { alive }\end{array}$ \\
\hline
\end{tabular}

ST sulfamethoxazole/trimethoprim, PSL prednisolone, $m P S L$ methylprednisolone, $P M$ pentamidine, $A Z A$ azathioprine, 5-ASA mesalazine, 6-MP 6mercaptopurine, ND not described

\section{Conclusions}

The findings of the present case suggest that the administration of an increased dosage of infliximab, as well as a general dose of infliximab, can cause Pneumocystis carinii pneumonia in CD patients, particularly in patients taking immunomodulators and/or steroids, illustrating the need for follow up, including pulmonary symptoms and $\mathrm{CT}$ examinations, when increasing the dosage of infliximab in CD patients.

\section{Consent}

Written informed consent was obtained from the patient for publication of this case report and accompanying images.

\section{Authors' contributions}

$\mathrm{TI}$ and AS were equally contributed to this study. TI, AS and MF conceived the report, collected data, and wrote the first draft of the report. AS and KT followed up the patient. YN, NU and SK performed endoscopy and evaluated the disease severity. SF, TG and JS evaluated radiological images including computed tomography. KM and IK supervised the study. All authors contributed to the critical revision of the report for important intellectual content. All authors read and approved the final manuscript.

\section{Acknowledgements}

We would like to thank Dr. Yuhei Inaba for his excellent suggestion and Dr. Tatsuya Utsumi and Dr. Hiroki Sato for significant assistances.

\section{Competing interests}

The authors declare that they have no competing interests.

Received: 13 December 2015 Accepted: 18 January 2016 Published online: 02 February 2016

\section{References}

1. Tai TL, O'Rourke KP, McWeeney M, Burke CM, Sheehan K, Barry M. Pneumocystis carinii pneumonia following a second infusion of infliximab. Rheumatology. 2002;41:951-2.

2. Mori S, Imamura F, Kiyofuji C, Ito K, Koga Y, Honda I, Sugimoto M. Pneumocystis jiroveci pneumonia in a patient with rheumatoid arthritis as a complication of treatment with infliximab, anti-tumor necrosis factor alpha neutralizing antibody. Mod Rheumatol. 2006;16:58-62.

3. Imaizumi K, Sugishita M, Usui M, Kawabe T, Hashimoto N, Hasegawa Y. Pulmonary infectious complications associated with anti-TNF alpha therapy (infliximab) for rheumatoid arthritis. Intern Med. 2006;45:685-8.

4. Kasai S, Tokuda H, Otsuka Y, Ookohchi Y, Handa H, Emoto N, Yoshikawa M. Two cases of respiratory infection complicating treatment with infliximab. Nihon Kokyuki Gakkai Zasshi. 2007;45:366-71.

5. Mori S, Tomita Y, Horikawa T, Cho I, Sugimoto M. Delayed spinal infection after laminectomy in a patient with rheumatoid arthritis interruptedly exposed to anti-tumor necrosis factor alpha agents. Clin Rheumatol. 2008:27:937-9.

6. Seddik M, Melliez H, Seguy D, Viget N, Cortot A, Colombel JF. Pneumocystis jiroveci (carinii) pneumonia after initiation of infliximab and azathioprine therapy in a patient with Crohn's disease. Inflamm Bowel Dis. 2004;11:618-20

7. Velayos FS, Sandborn WJ. Pneumocystis carinii pneumonia during maintenance anti-tumor necrosis factor-alpha therapy with infliximab for Crohn's disease. Inflamm Bowel Dis. 2004;10:657-60.

8. Kaur N, Mahl TC. Pneumocystis carinii pneumonia with oral candidiasis after infliximab therapy for Crohn's disease. Dig Dis Sci. 2004;49:1458-60.

9. Stratakos G, Kalomenidis I, Papas V, Malagari K, Kollintza A, Roussos C, Anagnostopoulou M, Paniara O, Zakynthinos S, Papiris SA. Cough and fever in a female with Crohn's disease receiving infliximab. Eur Respir J. 2005;26:354-7.

10. Itaba S, Iwasa T, Sadamoto Y, Nasu T, Misawa T, Inoue K, Shimokawa H, Nakamura K, Takayanagi R. Pneumocystis pneumonia during combined therapy of infliximab, corticosteroid, and azathioprine in a patient with Crohn's disease. Dig Dis Sci. 2007;52:1438-41.

11. Kanai H, Noguchi T, Koyanagi H, Marubashi K, Saruya S. Infliximab treatment in a hemodialysis patient with relapse of Crohn's disease after a 40-year interval. Dial Ther. 2009;42:905-10.

12. Tschudy J, Michail S. Disseminated histoplasmosis and pneumocystis pneumonia in a child with Crohn disease receiving infliximab. J Pediatr Gastroenterol Nutr. 2010;51:221-2. 